\title{
REPRESENTAÇÕES SOCIAIS DE PROFESSORES DO ENSINO SUPERIOR: UM ESTUDO DE CASO EM EDUCAÇÃO AMBIENTAL
}

Adalberto Ferdnando Inocêncio ${ }^{1}$

Resumo: $O$ recorte analítico desta pesquisa buscou investigar as Representações Sociais (RS) que professores do curso de Ciências Biológicas tem do conceito de meio ambiente $A$ hipótese foi a de que, com base nas RS que se tem sobre meio ambiente, inferem-se abordagens de Educação Ambiental (EA). Na perspectiva das RS meio ambiente não é entendido como conceito científico, mas uma terminologia permeada por representações circulantes em uma determinada sociedade. Para a coleta de dados, contou-se com uma entrevista estruturada composta de sete questões, direcionada a onze professores Os resultados são apresentados em núcleos distintos, categorizados conforme as RS diferentes que assumem. Notou-se o predomínio de RS de meio ambiente como um lugar físico, aproximando-se do conceito científico de ecossistema.

Palavras-chave: Meio Ambiente; Formação de Professores; Ecossistema. 


\section{Introdução}

Esta investigação nasceu de incômodos gerados durante a formação inicial (graduação) do autor deste texto no curso de Ciências Biológicas de uma universidade estadual do estado do Paraná (PR), mais precisamente de uma tendência identificada como separatista e intransponível entre o que se pode referir por saberes curriculares e saberes transversais, no caso aqui considerado, a EA. Tal formação fora caracterizada pela extensa malha dos conteúdos científicos, abordados, muitas vezes, sob uma perspectiva neutra de ciência, na qual os conteúdos são apresentados num viés acumulativo ao longo de uma história que, por sua vez, está desvinculada de interesses, de um problema, de uma pergunta, um contexto social ou, até mesmo, por pressão de certos grupos da sociedade civil organizada (CACHAPUZ et. al., 2011).

Parte desse incômodo, e também como indagação de pesquisa, residiu no fato de que alguns pesquisadores em EA vistos na literatura eram biologos de formação, como Marcos Reigota, Martha Tristão, Genebaldo Freire Dias, Carlos Bernardo Loureiro, Philippe Pomier Layrargues, Leandro Belinaso Guimarães e Angélica Góis Morales, para ficar nesses exemplos. Nesse ínterim, questões iniciais surgiram: cursos de licenciatura em Ciências Biológicas presentes em outras instituições oferecem fundamentação para se trabalhar com EA? Se não oferecem, em que momentos esses autores desenvolveram esses saberes? Desenvolveram durante as formações complementares, como cursos e palestras, ou somente quando cursaram a pós-graduação?

Nesse sentido, ao mesmo tempo em que a literatura chamava a atenção para a necessidade de discussão das questões ambientais na formação dos profissionais formados nas áreas de licenciatura, um levantamento e estudo da grade curricular do curso de Ciências Biológicas (nas periodicidades integral e noturno) da instituição investigada demonstrou isenção ao oferecer formação para as problemáticas necessárias em EA no âmbito formal. Contudo, reiterase que pelo âmbito institucionalizado das políticas é aconselhado que tal abordagem seja trabalhada de maneira transversal no currículo, como reconhece e institui a própria Política Nacional de Educação Ambiental ${ }^{2}$. Desse modo, apesar de não estar anunciada no currículo formal, não se descarta a possibilidade de que a EA seja exercida e praticada durante qualquer disciplina do curso, sendo possível sua implementação até mesmo como abordagem disciplinar, desde que seja em algum programa de pós-graduação, julgada a necessidade. O reconhecimento dessas questões levou à necessidade da pesquisa de campo. Apresentam-se, a seguir, algumas considerações que nortearam essa investigação.

2 Refere-se à Lei 9.795/1999.

Revbea, São Paulo, V. 14, № 4: 120-158, 2019. 


\section{Caminhos percorridos da Educação Ambiental: explorando o território investigativo}

Como já fora salientado, na experiência adquirida durante formação inicial do referido curso, percebeu-se que a dimensão ambiental (quando fomentada) ficava aos moldes de abordagens superficiais e panfletárias e, quando aprofundada, assumia a perspectiva das Ciências Naturais, galgadas em suas terminologias, apenas. Nos moldes da grade curricular considerada, não se identificava nenhuma tendência brasileira de Educação Ambiental (EA).

Com essas impressões iniciais, forjou-se a hipótese de que esses direcionamentos oferecidos no curso eram consequência de representações que os professores desenvolveram ao longo de sua própria formação, de modo que esta não se limita ao âmbito formal, mas também ao não-formal e informal, uma vez que a mídia ocupa um lugar de destaque na circulação contemporânea das discussões que permeiam o meio ambiente e suas esferas circunvizinhas (CARVALHO, 2006).

Autores como Marcos Reigota (2010) investigaram a formação de alguns professores nos cursos de licenciatura e, em um estudo de caso em que predominavam, principalmente, professores de Biologia, ele situa que não há posicionamentos universais e nítidos acerca de conceitos centrais para as diversas correntes em EA existentes no Brasil. No caso das Ciências Biológicas, há grande influência de disciplinas das Ciências Naturais e, em outro estudo, o autor chega a afirmar que essa influência é um dos fatores responsáveis pela confusão conceitual que se tem entre EA e Ensino de Ecologia (REIGOTA, 2009).

O objeto de estudo da Ecologia é a biosfera, a relação que os seres vivos ou fatores bióticos, se relacionam com o meio físico, os fatores abióticos. Ao passo que definir o objeto de estudo da EA, suas estratégias, o que almeja e como desenvolve suas intervenções, são tarefas muito mais complexas, envolvendo as Ciências Biológicas, mas, também um embasamento teórico proveniente das Ciências Humanas e até das Ciências Exatas (PELICIONI; PHILIPY JR., 2005). Na tendência da EA crítica, especificamente, um de seus objetivos é o de proporcionar melhor qualidade de vida aos sujeitos, percebendo-se de forma explícita a dimensão política permeando sua proposta educativa. A confusão entre EA e o Ensino de Ecologia que se tem no Brasil assinala o intercurso das décadas de 1960 a 1980, mas não se resume a esse recorte temporal, uma vez que as representações que se tem dessas terminologias podem persistir no decorrer das décadas seguintes, haja vista que, uma vez aceitas socialmente como realidade, as representações podem persistir em uma sociedade ou grupo de sujeitos por tempo indeterminado (MOSCOVICl, 2010).

Outro aspecto que contribui para a confusão conceitual acima referida é o fato de que a EA foi resultado de embates políticos liderados por movimentos ambientalistas, situando-se na confluência dos campos ambiental e educativo. Embora tenha recebido o adjetivo ambiental, as perspectivas iniciais da EA não

revista brasileira educação ambiental 
emergiram das teorias educacionais, o que implica estar mais relacionada "aos movimentos ecológicos e ao debate ambientalista do que propriamente ao campo educacional e à teoria da educação" (CARVALHO, 2006, p. 46).

$\mathrm{Na}$ atual conjuntura, a EA está mais próxima de uma área interdisciplinar $^{3}$, figurando-se num limiar entre as Ciências Naturais, Exatas e Humanas (PELICIONI, PHILIPPI JR., 2005) que, por sua vez, está atravessado pelas flutuações históricas e relações de poder imanentes a elas. A EA é um produto de investidas de movimentos sociais, mais precisamente do ambientalismo, que passou a reconhecer uma série de fatores que caracterizam uma crise ambiental recente na história das sociedades ocidentais e orientais, mas, também, de outras revoluções sociais, das guerras, das crises históricas, dos sistemas econômicos adotados em cada nação, do ataque aos biomas, dos dilemas que encetam as discussões sobre desenvolvimento e crescimento populacional, da Biologia da Conservação, das conferências oficiais e dos fóruns globais, dos documentos oficiais e textos não oficiais, da política de sistemas nacionais, das discussões e projetos que permeiam as escolas e centros educativos, das ONG e outras associações não governamentais, das representações midiáticas veiculadas por programas de TV, pelas revistas e pelos jornais, dos embates políticos e propostas de candidatos e partidos, e uma série de outras materialidades discursivas capazes de movimentar e ensejar as representações que compõem o imaginário brasileiro do que seja esta área de conhecimento.

Frente a essa pluralidade de enunciados flutuantes, as perspectivas metodológicas que guiaram essa investigação ancoraram-se nas considerações instrumentais reconhecidas por Marcos Reigota (2010) desde a década de 1990, de que essa pluralidade de perspectivas e práticas que tem sido vistas em EA decorrem da noção de meio ambiente a ela subjacente. Desse modo, ao invés de um conceito científico, meio ambiente é uma Representação Social, haja vista que não se tem um consenso sobre essa terminologia na comunidade científica. Seu caráter é difuso e varia conforme as distintas áreas e profissionais do conhecimento que a ela se referem. Apresentadas essas características, concorda-se com Trivelato e Silva (2011, p. 17) de que "o primeiro passo para a realização da Educação Ambiental deve ser a identificação das representações das pessoas envolvidas no processo educativo". Além disso, [...] "toda forma de pensar se insere em uma situação histórico-social concreta e deve ser compreendida sempre se tendo em vista sua configuração coletiva específica" (REIGOTA, 2010, p. 70), entendida aqui como o espaço científico de formação.

Disso decorre que o que tem sido chamado de EA nas instituições formais pode tanto estar ancorado nos pressupostos científicos e filosóficos apresentados e propostos nos documentos, leis, tendências e resultados de investigação que se fazem circular tanto na esfera acadêmica quanto fora dela,

\footnotetext{
${ }^{3}$ Como está disposto na Lei anteriormente referida.
} 
quanto ser resultados do que se acredita serem práticas de "bom senso", veiculadas por diversas plataformas de comunicação que não se operacionalizam, necessariamente, por um crivo científico.

Sabendo que a veiculação da terminologia meio ambiente em uma pluralidade de instâncias influencia as condutas educativas, cabem aqui as seguintes considerações de Carvalho:

Quando falamos em meio ambiente, muito frequentemente essa noção logo evoca as ideias de "natureza", "vida biológica", "vida selvagem", "flora e fauna". Tal percepção é reafirmada em programas de TV como os tão conhecidos documentários de Jacques Cousteau ou da National Geographic e em tantos outros sobre a vida selvagem que moldaram nosso imaginário acerca da natureza. Até hoje esse tipo de documentário serve de modelo para muitos programas ecológicos que formam as representações de meio ambiente pela mídia. Essas imagens de natureza não são [...] um retrato objetivo e neutro [...] mas traduzem certa visão de natureza que termina influenciando bastante o conceito de meio ambiente disseminado no conjunto da sociedade. Essa visão "naturalizada" tende a ver a natureza como o mundo da ordem biológica, essencialmente boa, pacificada, equilibrada, estável em suas interações ecossistêmicas, o qual segue vivendo como autônomo e independente da interação com o mundo cultural humano (CARVALHO, 2006, p. 35 grifo nosso).

Nessa visão frequente, descrita pela autora, geralmente quando a presença humana aparece na interação com o meio ambiente aparece de forma amiúde. Ora aparece como problemática e nefasta para a natureza, ora colaboradora para sua conservação, como é o caso das perspectivas provenientes de "saberes das margens" ou provenientes das populações ribeirinhas e dos assentamentos rurais (REIGOTA; DO PRADO, 2008). Seus efeitos dependerão de quais representações orientarão suas práticas.

Não foi intenção desta investigação categorizar as representações e práticas delas decorrentes em "positivas" ou "negativas", mas, assumir que certos discursos são imanentes a práticas sociais que, por sua vez, produzem efeitos distintos à medida das representações as quais estão ancoradas (MOSCOVICI, 2010). Trata-se de reconhecer o caráter ideológico de certas correntes que podem, inclusive, se dizer ecológicas mas que continuam operando nas bases representativas erigidas pelo sistema capitalista, em nada descontruindo suas práticas sociais. Nesse sentido, não se intenta menosprezar a formação dos professores entrevistados, até porque suas representações são discursos eleitos de setores mais amplos de uma sociedade, mas se reconhece que certas representações podem trazer consequências gravíssimas em todos os níveis de ensino, bem como suas 
modalidades, o que reflete, em maior prazo, nas posturas adotadas por indivíduos diante da crise ambiental que se tem evidenciado a partir da segunda metade do século passado.

Nesse sentido, é essencial pensar no imaginário que se forma no campo do professorado, pois, em última análise, é o professor quem muitas vezes apresenta tais quadros sociais para os alunos, incluindo os fatores interventores do campo ambiental, ainda que distorcidos ou enviesados. Ao mesmo tempo em que este profissional pode reafirmar as concepções perpassadas pelos setores informais, pode desconstruí-las para reafirmar novos valores.

O fator chave reside na transposição didática dos documentos e leis que figuram no acontecimento ambiental contemporâneo para a prática docente, ou seja, apesar de vivenciarmos um momento histórico que se caracteriza pela institucionalização da EA em diversas perspectivas (REIGOTA, 2009), o mesmo pode não acontecer no domínio das práticas docentes cotidianas. A leitura dos acontecimentos pelas "lentes" das Representações Sociais permite demonstrar que o domínio científico "escapa" às práticas cotidianas, prevalecendo, em inúmeras situações (neste caso, profissionais) as regularidades discursivas orientadas por valores do senso comum veiculados numa cultura determinada.

Este trabalho apresenta resultados parciais de uma investigação realizada no ano de 2012 envolvendo onze docentes do curso de Ciências Biológicas de uma universidade estadual. Buscando conhecer as Representações Sociais que os mesmos movimentam acerca de terminologias como meio ambiente, delinear-se-á de que modo os mesmos concebem abordagens possíveis de EA.

Por razões que foram apresentadas até aqui, apostou-se que por meio dos dados obtidos tornar-se-ia possível conhecer potencialidades e limitações que a EA encontra na prática pedagógica desses professores. A análise desses dados demonstra uma perspectiva possível acerca de como uma política nacional vem sendo trabalhada num curso de ensino superior. Por fim, no recorte aqui considerado, apresentam-se e discutem-se as representações de meio ambiente, divididas em dois núcleos de representações.

\section{As representações sociais: acentuando o enfoque teórico-metodológico}

Do ponto de vista teórico-metodológico adotou-se a Teoria das Representações Sociais (TRS), desenvolvida por Serge Moscovici no limiar da década de 1960. A Representação Social (RS) é definida por este autor como "um corpus organizado de conhecimento e uma das atividades psíquicas graças a qual os homens tornam inteligível a realidade física e social" (MOSCOVICI, 1978, p. 91). Nesse sentido, as RS também são um sistema de valores e práticas orientado com uma dupla função: "estabelecer uma ordem que possibilitará as pessoas orientar-se em seu mundo material e social e 
controlá-lo", bem como, "possibilitar que a comunicação seja possível entre os membros de uma comunidade, fornecendo-lhes um código para nomear e classificar os vários aspectos de seu mundo" (MOSCOVICl, 2010, p. 21).

Pode-se dizer que a TRS foi desenvolvida numa perspectiva voltada à apreensão dos conteúdos de composição e dos processos envolvidos na formação das representações individuais, sendo, segundo Moscovici (1978, p. 174) "uma instância no domínio do ser e outra no domínio do fazer". São as representações que certo grupo possui sobre determinado tema que contribuem ou mesmo determinam a organização de seu modo de viver, haja vista que, na perspectiva do mesmo autor, uma representação é social na medida em que contribui para os processos de formação de condutas orientadas pela cultura.

Apresentado o conceito, faz-se importante visibilizar que as RS podem exercer, em uma determinada sociedade, o papel de convenção e o de prescrição. O primeiro opera por dar uma forma definitiva a um objeto, localizando em uma determinada categoria que, gradualmente, constrói um modelo de determinado tipo, cujo objetivo final é o de ser partilhado por um grupo de pessoas (MOSCOVICl, 2010). Ao convencionar um objeto, uma RS coloca-o em circulação na cultura partilhada por uma sociedade. Por sua vez, o segundo tem o papel de impor formas de pensar e agir sobre o grupo social que partilha determinadas RS. Deste modo, o conteúdo presente nos jornais, nos discursos políticos e nos filmes acabam por veicular representações, "que são partilhadas por tantos, penetram e influenciam a mente de cada um, mesmo não sendo pensadas por eles" (MOSCOVICl, 2010, p. 37).

As RS acabam por convencionar e prescrever uma vez que visam transformar um objeto que não é familiar em familiar para uma determinada sociedade. Moscovici (2010) argumenta que toda sociedade evoca mecanismos que trabalham para tornar um objeto desconhecido em categorias conhecidas, de modo a comunicar processos que antes assumiam um caráter de não familiar. Ao evocar esses mecanismos, o "[...] pensamento social deve mais à convenção e à memória do que à razão; deve mais às estruturas tradicionais do que às estruturas intelectuais ou perceptivas correntes" (MOSCOVICl, 2010, p. 57). Isso explica por que mesmo nas sociedades ocidentais, nas quais a crise ambiental figura-se como um paradigma em evidência - movimentando uma série de terminologias científicas para se referir a ela -, pode ser comum que se evidenciem o senso comum e a opinião como formas predominantes de comunicação.

Nesse sentido, a TRS é possibilidade de um referencial teórico e instrumental quando se considera trabalhar com grupos sociais (objeto de estudo nessa investigação). Na perspectiva da EA, esta vertente mostra-se útil na identificação dos conhecimentos e das práticas sociais que se articulam no espaço em que se relacionam sociedade, ambiente e cultura.

Em termos práticos, podemos inferir que a participação e envolvimento dos atores sociais (nesse caso, professores) com as questões ambientais, seja

revista brasileira educação ambiental 
na resolução de problemas, tomada de decisão ou formação de opinião, estão relacionados às diferentes RS que esse público tem de meio ambiente, natureza, sustentabilidade e outros termos envolvidos a essa esfera. Trabalhar na construção desta interface: EA e TRS é articular em sua abordagem teórica e prática uma ação mediadora de interesses e conflitos dos grupos que realizam determinadas atividades e ocupam espaços precisos partindo de interesses muitas vezes individuais, e, portanto, singulares.

Apesar de já ter sido instituída formalmente, e o número de obras sobre este assunto ter crescido consideravelmente no Brasil e fora dele, sendo vistas inúmeras publicações que trazem em seu bojo fundamentos, metodologias e ações, percebe-se claramente que nas agências de ensino formal - Ensino Fundamental, Ensino Médio e Ensino Superior - este campo de saberes ainda apresenta dificuldades em ser tratado e discutido na perspectiva transversal e interdisciplinar, como orienta a Política Nacional de Educação Ambiental, ratificada e aprovada em 1999 e regulamentada em 2002 na Lei 9.795, de 27 de abril de 1999 (objeto do Decreto 4.281, de 25 de junho de 2002). Essas dificuldades, referidas anteriormente, estão situadas num distanciamento das normativas e sugestões orientadas pela institucionalização das Leis e documentos oficiais, e daquilo que se efetiva, de fato, nas trocas cotidianas das aulas e das abordagens de ensino.

A Educação Ambiental muito tem avançado no âmbito da política institucionalizada internacional e nacionalmente, sendo que suas estratégias e planos de ação já aparecem sendo recomendadas pelos documentos oficiais e não oficiais, como a Carta de Belgrado, a Agenda 21, a Carta da Terra, a Declaração das Nações Unidas para o Meio Ambiente Humano, a Declaração das Nações Unidas para o Meio Ambiente e Desenvolvimento, os Parâmetros Curriculares Nacionais e o documento de maior destaque na orientação da EA em território brasileiro, o Tratado de Educação Ambiental para Sociedades Sustentáveis e Responsabilidade Global. A questão que se coloca é "de que modos temos discutido meio ambiente no âmbito educacional?" Ao lecionarem Ciências Biológicas, "que posições esses professores adotam quando meio ambiente é imerso num território político, como quando aparece em temas relacionados ao novo código florestal, ao agronegócio e aos alimentos transgênicos?"

Entende-se que a educação dada é constituída de marcas e desejos socialmente compartilhados, não apenas individuais, que determinados sujeitos sociais querem inscrever na ação educativa, qualificando suas práticas educativas no interior de um universo de crenças e valores endereçado à educação. Essas marcas inscrevem algo que não estava desde sempre aí, na educação tomada no seu sentido mais genérico. Deixam aparecer algo novo, uma diferença, uma nova maneira de dizer, interpretar e validar um fazer educativo que não estava dado na grande narrativa da educação (CARVALHO, 2006). É deste modo que se explica, em partes, o aspecto fugidio das representações quando comparadas aos conceitos científicos: não é porque exista o conceito universalmente aceito de um dado objeto que seu sentido 
permanece intacto no complexo social. O sentido também é permeado por ampla dose de senso comum que está imanente nas sociedades em que se investiga (JOVCHELOVITCH, 2008; MOSCOVICI, 1978).

Cientes de que para identificação das Representações Sociais de meio ambiente, podem-se utilizar a análise do discurso escrito, interpretação de imagens, análise de textos de jornais e revistas, discussões coletivas etc. (TRIVELATO; SILVA, 2011, p. 26), esta investigação compôs-se de um questionário dotado de sete questões estruturadas, em roteiro previamente estabelecido, uma vez que os conteúdos expressos como respostas às mesmas questões seriam comparados entre si e confrontados com o que traz a literatura, interessando as proximidades e descontinuidades dos conteúdos obtidos (MARCONI; LAKATOS, 2010).

Após o projeto referente ao trabalho de conclusão de curso (do qual são recortados os resultados parciais que compõe este texto) ter sido aprovado pelo Comitê Permanente de Ética em Pesquisa com Seres Humanos (COPEP), foram entrevistados onze professores efetivos do curso de Ciências Biológicas de uma universidade do estado do Paraná. Buscando contemplar a maior expansão de áreas do conhecimento possível, optou-se pela escolha de um professor/área de conhecimento, sendo suas respectivas atuações em disciplinas diferentes do mesmo curso: zoologia, botânica, anatomia, parasitologia, micologia, ensino de ciências, dentre outras. Enfatiza-se que, além da aprovação do projeto pelo comitê de ética, todos os professores assinaram um termo de consentimento livre e esclarecido acerca de sua participação nesta pesquisa.

As questões que compunham o questionário estruturado eram as seguintes: 1. O termo meio ambiente é concebido de diversas formas. Qual a sua concepção de meio ambiente? 2. Com o termo natureza acontece de forma similar. O que você entende por natureza? 3. O que seria, pra você, comportamento ecológico? E consciência ecológica? 4. Há diversas definições sobre desenvolvimento sustentável. Você teve acesso a alguma delas? Como você $\mathrm{a}(\mathrm{s})$ vê? 5. Muito se fala sobre Educação Ambiental, sobre sua necessidade nas pesquisas, na mídia, em publicações, textos, políticas públicas, dentre outros setores. Desses aspectos expostos, existe algum que você utiliza em suas aulas e que envolve esse assunto? 6. De que forma(s), em suas aulas, a Educação Ambiental poderia ser tratada? E, finalmente 7. Em seu entendimento, a Educação Ambiental deve ser trabalhada em alguma disciplina específica?

No recorte analítico dedicado a esse texto, delimitou-se por apresentar e discutir as RS de meio ambiente, não estendendo para conceitos mais elaborados como o de desenvolvimento sustentável, comportamento ou consciência ecológica, ou até mesmo de natureza. Após a coleta dos dados por meio da pesquisa estruturada, o corpus analítico foi analisado conforme a análise de conteúdo de linha francesa (BARDIN, 2011). Considerando as representações de meio ambiente em suas recorrências e descontinuidades, 
foram construídas duas categorias de análise, apresentadas e discutidas a seguir. Em um momento posterior discute-se o rumo dessas representações e os modos com que estas delineiam condutas possíveis em Educação Ambiental.

\section{As representações de meio ambiente e as práticas educativas em EA}

Com relação às $R S$ de meio ambiente obtidas nesse estudo, houve predomínio em concebê-lo como meio físico e natural, ou seja, como um local, sendo possível evidenciar mais facilmente essa concepção pelo aparecimento do advérbio onde. Como essa concepção figura nos resultados de forma quase unânime, tornou-se necessário sistematizá-la em duas subcategorias: 0 de compreensão de meio ambiente como espaço físico, e o de compreensão de meio ambiente como categoria política, sendo que, na segunda categoria houve apenas um sujeito da pesquisa contribuindo nesta concepção.

$\mathrm{Na}$ categoria predominante (meio como espaço físico), aparecem núcleos diversos e derivados, que se convencionou categorizar da seguinte forma: RS de meio ambiente como ecossistema, a RS de meio ambiente como segunda natureza e a RS de meio ambiente que incorpora a dimensão cultural.

Assim, no $1^{\circ}$ núcleo - meio ambiente como de ecossistema, podemos notar as seguintes representações:

"Pra mim ele é bastante amplo. Pode ser no sentido de onde a gente está situado, do espaço, o espaço fora e eu também posso incluir o espaço dentro. Não só um espaço físico, também as relações que ocorrem ali, com os organismos, com as pessoas, é o que envolve tudo isso."

"Todo o espaço que você ocupa na sua vivência, não necessariamente o ambiente natural mas todo o espaço que você usa durante suas atividades, enfim, durante a sua vida. Não é uma coisa muito limitada não, é abrangente".

"Pra mim meio ambiente é qualquer espaço, né, que seja habitado por qualquer forma de vida, e eu tenho uma ideia de associar ambiente à formas vivas. Então eu acho que é um espaço que é habitado, ou aproveitado de alguma forma por algum ser vivo".

Em tais representações ficam evidentes traços biológicos que se aproximam do conceito de ecossistema, objeto de estudo da Ecologia. Vejamos algumas definições de ecossistema cedida por alguns autores da área. Odum (2008 p. 18) considera sistema ecológico ou ecossistema como "uma unidade que inclui todos os organismos (a comunidade biótica) em uma dada área interagindo com o ambiente físico de modo que um fluxo de energia 
leve a estruturas bióticas claramente definidas e à ciclagem de materiais entre componentes vivos e não vivos". Townsend, Begon e Harper (2010, p. 403) destacam que o termo ecossistema "é usado para denotar a comunidade biológica juntamente com o meio abiótico no qual a mesma está inserida". Ricklefs (2009, p. 2), por sua vez, aponta que o conceito se refere aos "conjuntos de organismos com seus ambientes físicos e químicos formam um ecossistema".

Embasados na concepção interativa entre os fatores/componentes bióticos (os seres vivos) e abióticos (não vivos) que, por sua vez, coexistem e ocupam um determinado espaço, que, para os sujeitos da pesquisa, é resumidamente físico, podemos afirmar que há um reducionismo em suas abordagens. A noção política e os direcionamentos econômicos, históricos e culturais são omitidos nessa composição com um ambiente estático e paisagístico. De que forma, numa dimensão problemática complexa, a ecologia poderia, por si só, ou mesmo com a ajuda das demais ciências ambientais, ou biológicas, solucioná-la?

"A Ecologia, desde seu surgimento, só se ocupou do equilíbrio entre os ecossistemas, do meio ambiente natural e do estudo das relações entre os seres vivos e não vivos, sem estabelecer relação entre esses e o sistema socioeconômico" (PELICIONI; PHILIPPI JR, 2005, p. 4). Assim, reconhece-se que a abordagem meramente técnica que se consubstancia em utilizar os conceitos ecológicos, não é capaz, por si só, de solucionar a complexa teia de relações que arquitetam as questões ecológicas da atualidade. "Embora a ecologia permaneça fortemente enraizada na biologia, ela emergiu desta como uma disciplina essencialmente nova e integrativa, que liga os processos físicos e biológicos, formando uma ponte entre as ciências naturais e sociais" (ODUM, 1977 apud ODUM, 2008). A ecologia, na atual conjuntura, tem perspectiva política, quando dimensionada aos movimentos sociais, mais precisamente 0 ecologista, que findou nas interfaces que hoje conhecemos tais quais a ecologia profunda (deep ecology), ecologia humana e agroecologia, ou agricultura ecológica. No entanto, este movimento não foi citado ou percebido nas respostas, que concebem um caráter meramente descritivo, aproximandose do conceito de ecossistema.

No $2^{0}$ núcleo - meio ambiente como conceito que se aproxima de segunda natureza, podem-se notar as representações:

"É o local onde as espécies interagem com os fatores físicos e químicos. Local onde as espécies interagem. Teria o ambiente urbano, o mais natural, diversos tipos. Meio ambiente é errôneo, é popular".

"Primeiramente pra mim não existe meio ambiente, existe ambiente e ambiente já é um meio. Já é o local onde se inserem as espécies biológicas. É o espaço, o local, não só o local, mas também as relações entre os organismos vivos, 
concebidos dentro da própria natureza. Esse ambiente inclusive pode ser um ambiente urbano, não precisa ser necessariamente natureza".

[...] "o ambiente é o local, seja natural ou não, onde todos os organismos vivem. A maior parte dos organismos está inserida de uma maneira natural, em ecossistemas naturais ou artificiais em que eles conseguem se adaptar. De forma natural ou não, é o meio onde os organismos estão inseridos, e se relacionam, desenvolvem suas atividades sociais. Mas é bem amplo, não fica restrito só à biologia ou a ecologia".

"É tudo. O natural e o alterado pelo homem né. É comum quando se fala em meio ambiente pensar em local preservado, área preservada, mas pra mim não. Meio ambiente é tudo. É o que já foi alterado e o que é natural. É o espaço físico".

Percebe-se nessa segunda tendência identificada, um nível de elaboração mais complexo se comparada à primeira, uma vez que o ser humano é, nesta perspectiva, dotado de potencial capaz de mudar seu espaço, e, não somente se adaptar com ele. Consideram nessa categoria, uma ambivalência do espaço físico que habitamos (perdura a noção de ambiente como dimensão físico-espacial), caracterizada no sentido de ambiente natural ou primeira natureza, e ambiente urbano ou segunda natureza, sendo que este passou pela interferência científica e tecnológica, desenvolvida pelo ser humano.

Assim, pode-se pensar numa relação dualista do papel educativo: o Homo sapiens é uma espécie diferente das demais, capaz de modificar seu espaço físico pelo trabalho, tecnologia ou ferramentas, não se adaptando a ele, mas, pelo contrário, adaptando o espaço de acordo com as suas necessidades, residindo aí, uma diferença primordial entre nós e o restante das espécies. Nesta acepção, a educação, ainda que em sentido técnico, capacita o sujeito com métodos e técnicas, calcadas no conhecimento científico e espacial, proporcionando-Ihe instrumentos materiais e funcionais para a modificação do contexto espacial que habita reconhecido nas falas como o espaço urbano, 0 meio alterado. Ao mesmo tempo em que o processo educativo permite repensar e reelaborar o tradicional, o status quo, na medida em que são capazes de intervir nas práticas pedagógicas correntes. É nesse sentido, que a preocupação com o ambiente problematiza as questões de transmissão e assimilação do saber preestabelecido, elaborado e aplicado de forma universal, descaracterizando as individualidades e culturas de uma dada região.

Tozoni-Reis (2004) colabora com algumas concepções que nos auxiliam a fundamentar essa categoria. Segundo ela, pensar a educação, implica reconhecer nesse processo dinâmico, um fenômeno essencialmente humano. Assim, nossa espécie é a única que se relaciona de forma diferente das outras com a natureza, sendo que somos os únicos capazes de transformá-las de forma significativa. Nesse sentido, "as consequências da ação intencional e 
transformadora dos homens no mundo são determinantes da crise ambiental planetária que se vêm desenvolvendo durante toda a história da humanidade" (TOZONI-REIS, 2004, p. 79-80).

Finalmente, no 3o núcleo - meio ambiente que incorpora as dimensões culturais, podemos notar:

\begin{abstract}
"É o local onde nós vivemos, desenvolvemos nossas atividades profissionais e com nossos familiares. Espaço físico e também a integração das pessoas que participam dele, inclusive o comportamento das pessoas nesse espaço físico, com relação a cultura, educação, enfim".

"Bom eu entendo meio ambiente como o ambiente onde estamos vivendo. A interação entre a parte biótica e abiótica. Acho importante, que inclua também a parte intelectual, que seria a influência do pensamento e comportamento sobre o ambiente que a gente está vivendo, acho que não tem como separar um do outro".
\end{abstract}

Consideramos que esse terceiro grupo de concepções figura numa dimensão mais complexa que as verificadas anteriormente, pois, apesar de manter o ideário de ambiente como espaço físico, incorpora as dimensões simbólicas, abstratas e culturais, inerentes da sociabilidade típica das formas de organização social. Esse ponto de vista caminha no sentido do desenvolvimento do sujeito em sua relação com o conhecimento, revelando uma forte posição interacionista, enriquecendo as relações sociais, ao mesmo tempo em que reflete uma postura dinâmica dessas relações: "a parte intelectual, que seria a influência do pensamento e comportamento sobre o ambiente que a gente está vivendo".

Valorizar o caráter dinâmico do conhecimento é valorizar seu componente histórico, contextual e, nesse sentido, reconhecer que o ideário, ou seja, as concepções paradigmáticas são passíveis de mudança, que a plêiade de conhecimentos e atitudes que organizam nosso imaginário, não será a mesma em um futuro muito próximo, ou distante. Essa representação leva, dentre outras coisas, a reconhecer que, "mais do que uma dimensão, uma variável ou um espaço de integração dos saberes constituídos, o ambiente é um processo de transformação do conhecimento impulsionado por uma crise da racionalidade econômica e instrumental da modernidade" (LEFF, 2011, p. 148). Nesse sentido, o imaginário de uma sociedade é o que de fato a mobiliza nas ações políticas, determinando, ou não, a promoção de estratégias que valorizem as potencialidades capazes de transformar, de fato, as relações sociedade e ambiente.

A consciência que uma sociedade tem de ambiente é a soma de valores, percepções, sensibilidades, do almejar por projetos alternativos de civilização, de vida, de um novo modelo de desenvolvimento em que caibam os grupos 
marginalizados, o questionamento de dogmas ideológicos, o reconhecimento dos usos sociais dos saberes científicos, os quais são constituídos pela ideia de paradigma e, portanto de mutabilidade.

Apresentados esses núcleos de RS sobre o meio ambiente, pode-se questionar: "Que noções de EA estão imanentes a essas representações?". Com base nelas, é possível traçar um panorama de imaginário que se faz num determinado grupo. Mauro Guimarães (2011) é um dos autores que lembra de que, ao longo desses 25 anos, apesar da grande difusão da EA no meio educacional, formal e não formal, tivemos no mesmo período uma maior degradação ambiental no Brasil e no mundo; ou seja, atualmente, apesar das preocupações no plano educativo, a sociedade moderna usufrui de forma mais predatória a natureza do que há 25 ou 30 anos. Isso nos faz no mínimo refletir: será que a educação não está fazendo problematizações de forma eficiente ou suficiente?

As RS de ambiente apresentadas aqui evocam conhecimentos importantes da parte do professorado, mas à medida que se encontram com problemas ambientais complexos das sociedades pós-industriais acabam por ficar num domínio instrumental, restringindo-se ao que Moscovici (2010) chama de "núcleo duro" ou central da RS, isso é, aquele núcleo de representações que resistem ao tempo e às transformações socioculturais de uma sociedade. Em um momento específico em que faz interlocução entre as RS e os paradigmas de uma dada sociedade, ele chega a afirmar que "conceitos que operam em grandes profundidades parecem necessitar mais de cinquenta anos para penetrar as camadas mais baixas da comunidade científica" (MOSCOVICI, 2010, p. 19). Apesar de haver um terreno consolidado no quesito das políticas institucionalizadas, não é garantia que o teor de tais textos e práticas estejam incorporados nas RS circulantes em uma comunidade, mesmo que seja esta pertencente à esfera científica.

Ainda assim, seria injusto desconsiderar a preocupação dos sujeitos participantes desta pesquisa com as questões ambientais. Mesmo os educadores que não conhecem as perspectivas movimentadas pelo pensamento crítico ou das outras vertentes em EA, reconhecem a importância de serem consideradas na atividade docente, o que possibilita uma difusão mais satisfatória da EA neste curso do ensino superior considerado. No entanto, diante dos dados de que os problemas socioambientais somente se agravaram nos últimos tempos, permanece atual a consideração de Guimarães:

Os educadores, apesar de bem-intencionados, geralmente ao buscarem desenvolver atividades reconhecidas como de Educação Ambiental, apresentam uma prática informada pelos paradigmas da sociedade moderna. [...] os indivíduos em geral, entre eles os educadores, seres sociais que somos, experienciamos em nosso cotidiano a dinâmica informada 
pelos paradigmas da sociedade moderna que tende a se autoperpetuar e que, segundo essa tendência, é reprodutora de uma realidade estabelecida por uma racionalidade hegemônica (GUIMARÃES, 2011, p. 23).

É na perspectiva dessa questão que o autor afirma que caímos numa "armadilha paradigmática". Nela, o educador por estar atrelado a uma visão de mundo paradigmática e, portanto, fragmentária, simplista, reduzida não apenas das questões ambientais, mas de outras questões, expressam uma incapacidade discursiva que permeia uma prática pedagógica fragilizada em $\mathrm{EA}$, tendendo a meramente reproduzir as concepções tradicionais do processo educativo, isso é, as representações de senso comum ou, quando conceitos científicos, aparecem padronizados e sem relação com a trama social.

\section{Conclusões}

Esta investigação demonstrou predominância nas RS de meio ambiente entendido como espaço físico, estático e paisagístico, aproximando-se da noção de ecossistema, objeto de estudo das ciências ecológicas. Nessas sequências enunciativas, as dimensões políticas e socioculturais, ou o que poderíamos definir como o ethos de uma sociedade, parecem ficar distantes desse da predominância das respostas.

A contribuição de uma investigação como esta, somada a inúmeras outras pesquisas de campo que se compõe pelas entrevistas a um grupo social, é evidenciar que uma sociedade pode institucionalizar orientações e abordagens, mas enquanto seu imaginário for "povoado" por feixes que se encetam de senso comum, os resultados práticos sofrerão influência dessa segunda instância. Não se trata de verificar isso como um problema, mas de reconhecer a importância de que práticas em EA devem ser delineadas com um levantamento das RS de um grupo, haja vista que essas intervirão na prática docente, qualquer que seja ela.

\section{Referências}

BARDIN, L. Análise de conteúdo. São Paulo: Edições 70, 2011.

BRASIL. Decreto-lei n. 9.795, de 27 de abril de 1999. Dispõe sobre a Educação Ambiental e institui a Política Nacional de Educação Ambiental e dá outras providências. Diário Oficial da União. Brasília, 1999.

CACHAPUZ, A.; GIL-PÉREZ, D.; CARVALHO, A.M.P.; PRAIA, J.; VILCHES, A. (orgs.). A necessária renovação do ensino de ciências. 3. ed. São Paulo: Cortez, 2011.

CARVALHO, I.C.M. Educação Ambiental: a formação do sujeito ecológico. 2. ed. São Paulo: Cortez, 2006. 
GUIMARÃES, M. Armadilha paradigmática na Educação Ambiental. In. LOUREIRO, C.F.B., LAYRARGUES, P.P.; CASTRO, R.S. (orgs.). Pensamento Complexo, Dialética e Educação Ambiental. 2. ed. São Paulo: Cortez, 2011.

JOVCHELOVITCH, S. Os contextos do saber: representações, comunidade e cultura. Petrópolis, Rio de Janeiro: Vozes, 2008.

LEFF, E. Saber ambiental: sustentabilidade, racionalidade, complexidade, poder. 8. ed. Petrópolis, RJ: Vozes, 2011.

MARCONI, M.A.; LAKATOS, E. M. Fundamentos de metodologia científica. 7. ed. São Paulo: Atlas, 2010.

MOSCOVICl, S. A representação social da psicanálise. Rio de Janeiro: Zahar, 1978.

MOSCOVICl, S. Representações sociais: investigações em psicologia social. 7. ed. Petrópolis, Rio de Janeiro: Vozes, 2010.

ODUM, E. Fundamentos de ecologia. São Paulo: Cengage Learning, 2008.

PELICIONI, M. C. F., \& PHILIPPI JR., Arlindo. Bases Políticas, Conceituais, Filosóficas e Ideológicas da Educação Ambiental. In. PELICIONI, M.C.F.; PHILIPPI JR., A. Educação Ambiental e Sustentabilidade. Barueri, São Paulo: Manole, 2005.

REIGOTA, M.; PRADO, B.H.S. Educação Ambiental: utopia e práxis (orgs.). São Paulo: Cortez, 2008.

REIGOTA, M. O que é Educação Ambiental. 2. ed. São Paulo: Brasiliense, 2009.

REIGOTA, M. Meio Ambiente e Representação Social. 8. ed. São Paulo: Cortez, 2010.

RICKLEFS, R. A Economia da natureza. Rio de Janeiro: Guanabara Koogan, 2009.

TOZONI-REIS, M.F.C. Educação Ambiental: natureza, razão e história. Campinas, SP: Autores Associados, 2004.

TOWNSEND, C.; BEGON, M.; HARPER, J. Fundamentos em ecologia. 3. ed. Porto Alegre: Artmed, 2010.

TRIVELATO, S.F.; SILVA, R.L.F. Ensino de Ciências. São Paulo: Cengage Learning, 2011. 